\title{
Immune complexes in myasthenia gravis
}

\author{
W ILHELMINA M. H. BEHAN A N P . O. BEHAN \\ From the Departments of Pathology and Neurology, University of Glasgow, Glasgow
}

S UMMARY Complement components were measured and immune complexes were sought in 75 patients with myasthenia gravis. Thirty-four per cent had decreased concentrations of complement component $\mathrm{C} 4$, and $29 \%$ had circulating immune complexes. The greatest immunological abnormalities were found in patients with mild disease which supports recent immunoelectronmicroscopic findings.

There is compelling evidence that myasthenia gravis is an autoimmune disease. An association with other autoimmune disorders is found (Simpson, 1960); germinal centres occur in the thymic medulla in $70 \%$ of cases (Castleman, 1966); disordered $\mathrm{T}$ cell function and its clinical manifestations has been demonstrated (Simpson et al., 1976); and both cell-mediated and humoral immunity to the acetylcholine receptor $(\mathrm{AChR})$ are present (Almon et al., 1974; Abramsky et al., 1975; Aharanov et al., 1975; Lindstrom et al., 1976; Richman et al., 1976).

Cell-mediated hypersensitivity to the AChR cannot be demonstrated in all patients, particularly young female myasthenics (Richman et al., 1976), so that the exact role of lymphocytes in myasthenia gravis is not known. However, serum from myasthenic patients is capable of reproducing the typical clinical and electromyographic features of the disease in mice (Toyka et al., 1975) which suggests a central role for humoral antibody. Antibodies to cholinergic receptor structures are found in $75 \%$ or more of patients with myasthenia gravis, and some workers have found a positive correlation between these antibodies and the severity of the disease (Lefvert et al., 1978). Others have not, and indeed babies of myasthenic mothers have been described who have been perfectly healthy although they had antireceptor antibodies (Lefvert et al., 1978; Barkas et al., 1979). Antibody alone, however, has been shown to increase the rate of degradation of junctional and extrajunctional acetylcholine receptors in muscle (Reiness et al., 1978).

\footnotetext{
Address for reprint requests: Dr P. O. Behan, University Department of Neurology, Institute of Neurological Sciences, Southern General Hospital, 1345 Govan Road, Glasgow G51 4TF.

Accepted 27 December 1978
}

A role for complement in myasthenia gravis was demonstrated by Strauss et al. (1960) when they described humoral antibodies to skeletal muscle $\mathrm{A}$ bands and pointed out that these antibodies were complement-fixing. Fluctuations in serum complement concentrations were then found (Nastuk et al., 1960) in the serum of 68 patients examined serially-decreased complement levels were shown in one or more serum samples from 40 patients. When the disease remitted, $50 \%$ of these patients demonstrated an increase in serum complement to the normal or supernormal range. Immune complexes of immunoglobulin $\mathbf{G}$ (IgG) and complement factor 3 (C3) have been identified at the motor endplate in myasthenics (Engel et al., 1977).

In the experimental model of myasthenia gravis produced by passive transfer of serum from man to mouse, a pathogenetic role for the complement system has been shown (Toyka et al., 1977). Complement depleted rats cannot be immunised to develop experimental allergic myasthenia gravis (EAMG) (Lennon et al., 1978). Finally, in EAMG, $\mathrm{C} 3$ has been shown together with IgG at the motor endplate (Sahashi et al., 1978).

We, therefore, examined the serum of 75 patients with myasthenia gravis to estimate concentrations of the complement components and to try to detect evidence of circulating immune complexes.

\section{Patients and methods}

Twenty-four male and 51 female patients with typical undisputed myasthenia gravis, whose ages ranged from 2 to 66 years, were studied. All patients had antiacetylcholine receptor antibody titres which were increased, and the majority had 
antistriated muscle antibodies. The disease varied from mild ptosis in some, to complete paralysis necessitating artificial respiration in others. Patients were classified according to the severity of their disease on a scale of 1 to 3 , with 3 representing the most seriously affected patients.

An attempt was made to estimate the complement components serially. From 10 patients only one sample could be obtained but from the remaining 65 at least two, usually three, and in the case of 15 patients, nine samples were evaluated, taken at intervals of at least two months. The study lasted two years.

The functional efficiency of the total complement system was assayed in terms of the total haemolytic complement activity (CH50 units) using a standard technique (Kent and Fife, 1963). The following components were measured in EDTA plasma by the single radial immunodiffusion technique, using monospecific antisera: Clq, C3, C4, and Factor B. Commercially available plates (Behringwerke) were used to estimate $\mathrm{C} 4$ concentrations. Concentrations of $\mathrm{C} 7$ were measured by the reactive lysis method using activated $\mathrm{C} 5 / 6$ (Thompson and Lachmann, 1970). Conversion products of $\mathrm{C} 3$ were sought by crossed antibody electrophoresis (Laurell, 1965) and of Factor B, by routine immunoelectrophoresis. The antisera used were prepared in our laboratory by standard techniques.

Immune complexes were looked for by the anticomplementary method as standardised by Mayer (1961). Serum anticomplementary activity was measured by incubating $0.1 \mathrm{ml}$ of heat-inactivated test serum $\left(56^{\circ} \mathrm{C}\right.$ for 60 minutes) with 2.5 units of guinea pig complement, at $37^{\circ} \mathrm{C}$ for 60 minutes. The residual anticomplementary activity was then titrated. In our laboratory immune complexes are normally considered present when less than $50 \%$ lysis occurs.

\section{Results}

Positive anticomplementary assays were obtained in 22 of the 75 patients. Serial testing of the patients revealed occasional reversal to give a negative result. The results are shown in Fig. 1, from which it can be seen that most of the positive assays were found in group 1, where $60 \%$ of the less severely affected patients had positive assays, compared with $15 \%$ of those with moderate myasthenia and $25 \%$ of those with incapacitating disease. Thus the positive assays tended to correlate with mild disease.

Estimation of the plasma complement components revealed conspicuous abnormalities in
$\%$ of positive assays
$\square \%$ of negative assays

Group 1 Mild disease

Group 2 Moderate disease

Group 3 Severe incapacitating disease

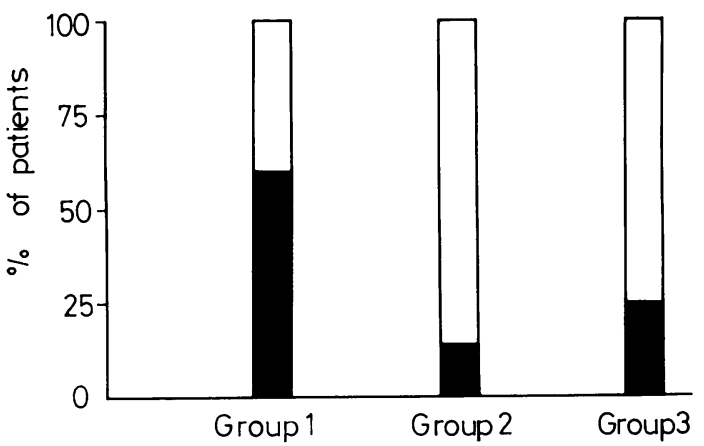

Fig. 1 Percentage of positive anticomplementary assays in 75 patients with myasthenia gravis.

component C4. Decreased concentrations of $\mathrm{C} 4$ were found in 26 of the 75 patients and increased concentrations in 18. Normal results were obtained in 31 patients. The normal plasma range in our laboratory is $31-55 \mathrm{mg} / \mathrm{dl}$, and the low levels found were from 13.5 to $28 \mathrm{mg} / \mathrm{dl}$ while the high levels were from 56 to $72 \mathrm{mg} / \mathrm{dl}$. In Fig. 2, the C4 concentrations are shown for each group, with the percentage of patients showing decreased, normal or increased $\mathrm{C} 4$ concentrations indicated. There was a conspicuous association between decreased $\mathrm{C} 4$ concentrations and mild or moderate

Decreased $\mathrm{C} 4$ concentration

图 Normal $\mathrm{C} 4$ concentration

首 Increased $\mathrm{C} 4$ concentration

Group 1 Mild disease

Group 2 Moderate disease

Group 3 Severe disease

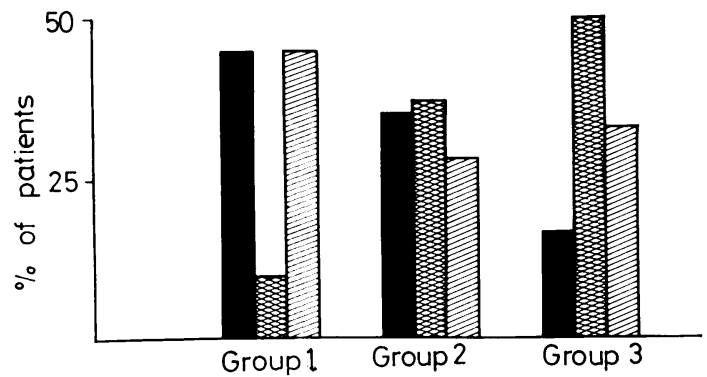

Fig. 2 Plasma C4 concentrations in 75 patients with myasthenia gravis. 
disease- $45 \%$ of patients in group 1 had low levels of $\mathrm{C} 4$ as did $35 \%$ of patients in group 2 . In patients with severe, incapacitating myasthenia gravis the percentage fell to $17 \%$.

Estimations of Clq, C3, and Factor B were normal, although the $\mathrm{Clq}$ and $\mathrm{C} 3$ concentrations tended to be in the low normal range. Estimations of $\mathrm{C} 7$ showed a good deal of variation. The $\mathrm{CH} 50$ unit estimations correlated well with the $\mathrm{C} 4$ results. Occasional C3 conversion products were detected in patients with decreased $\mathrm{C} 4$ concentrations but no conversion of Factor B was found.

In each group some patients showed increased C4 concentration above the normal range- $-45 \%$ in group $1,28 \%$ in group 2 , and $33 \%$ in group 3.

During the period of study, where serial measurements were made, the results were essentially similar on each occasion.

\section{Discussion}

There has long been circumstantial evidence suggesting complement involvement in the pathogenesis of myasthenia gravis. Early studies showed that sera from myasthenic patients were capable of lysing the surface cells of a preparation of frog sartorius muscle (Nastuk et al., 1959). The active principle in these sera was heat-labile and destroyed on heating at $56^{\circ} \mathrm{C}$ for one hour. Involvement of complement was suspected, and indeed an inverse correlation between serum complement concentration and disease activity in myasthenic subjects was then reported in a preliminary study (Nastuk et al., 1956). A large group of myasthenic patients was next investigated with serial estimations of complement concentrations. A close correlation was shown with decreases in complement paralleling disease activity. Associated virus or bacterial infections were ruled out (Nastuk et al., 1960).

In 1973 it was shown that rabbits immunised with acetylcholine receptor (AChR) provided an experimental model for myasthenia gravis (Patrick and Lindstrom, 1973). Further studies revealed a factor in the serum of myasthenic subjects capable of binding to purified AChR (Almon et al., 1974; Bender et al., 1975). A role for complement was suggested by experiments in which myasthenic serum passively transferred to mice produced clinical signs in the recipients which were significantly less if the mice were depleted of C3 (Toyka et al., 1977). In addition, EAMG could not be induced in rats depleted of complement by intraperitoneal inoculation of cobra venom factor (Lennon et al., 1978). Thus, complement appeared to be essential for AChR antibodies to be pathogenic.
Recently there have been elegant demonstrations of immune complexes (IgG and C3) at the motor endplate in myasthenic patients. The deposits of IgG and C3 were localised to the segments of the postsynaptic membrane where acetylcholine is known to be distributed, and were also found on degenerating junctional folds in the synaptic space (Engel et al., 1977). Immune complexes were much more sparse and difficult to find in the severe myasthenics. In EAMG, similar studies have been made of the motor endplates, and similar complexes of IgG and C3 have been identified on the terminal expansions of the junctional folds and on detached fragments of these folds in the synaptic space. Similarly, complexes were present in decreased amounts in the more severe cases of EAMG (Sahashi et al., 1978). These findings were attributed to the fact that in severe myasthenia gravis or EAMG a smaller quantity of AChR remains at the endplates. The length of postsynaptic membrane on which immune complex deposits were found correlated with the miniature endplate potential (mepp) amplitude, as would be expected, since it had been shown previously that there was a linear relationship between the mepp amplitude and the amount of postsynaptic membrane reacting for AChR (Engel et al., 1977). All these results suggest that the reduction in AChR is secondary to complement-mediated damage.

In the in vitro situation, using EAMG rat sera and innervated rat diaphragm in organ culture, AChR antibody has been shown to have two effects: to bind to AChR and, more importantly, to increase the rate of degradation of $\mathrm{AChR}$ (Heinemann et al., 1978; Reiness et al., 1978). The latter effect of antigen modulation appears to be complement independent in this model. In vivo, however, the involvement of complement has been clearly shown (Engel et al., 1977).

Our finding of a decreased serum concentration of CH50 units in patients with myasthenia gravis agrees with that of previous workers (Strauss et al., 1960). We used a more accurate and standardised microtechnique (Mayer, 1961) and found the best correlation with the plasma $\mathrm{C} 4$ concentrations. The Clq, C3, and Factor B estimations fell within the normal range; $\mathrm{C} 7$ concentrations showed wide variation. In the cases with low $\mathrm{C} 4$ concentrations, some conversion of $\mathrm{C} 3$ was frequently detectable. Conversion of Factor B was not found. Thus, the findings confirm that there is classical pathway utilisation of complement and that it is the early components of the cascade which are most involved (Toyka et al., 1977).

In the original study (Strauss et al., 1960) 60\% 
of patients showed decreased serum complement. We found that, overall, $34 \%$ of myasthenic patients had reduced $\mathrm{C} 4$ concentrations but, as can be seen in Fig. 2, the percentage of patients showing this reduction reached $45 \%$ in those least affected, was $35 \%$ in those with moderate disease, and fell to $17 \%$ in patients with severe myasthenia. It is of great interest that the depression of C4 occurred most frequently in the least affected patients, because this may be explained by previous observations on deposition of immune complexes at the muscle endplate (Engel et al., 1977). We also confirm the finding of Strauss et al. (1960) of wide variations in serum complement. Increased $\mathrm{C} 4$ concentrations were detected in $24 \%$ of the patients. These results suggest that complement metabolism should be investigated in myasthenic patients.

The anticomplementary assays were positive in $30 \%$ of our cases, suggesting the presence of circulating immune complexes. There was a much higher percentage of positive results $(60 \%)$ in the less severely affected myasthenics than in those with incapacitating myasthenia gravis $(30 \%)$. Circulating immune complexes have been sought in small groups of patients with myasthenia gravis by other investigators. Casali et al. (1976) detected complexes in seven of eight patients, using the Clqbinding assay. In five of the eight patients there was an associated decrease in the serum $\mathrm{C} 4$ concentration. On the other hand. Tachovsky et al. (1976) found no serum antigen-antibody complexes in five patients with myasthenia gravis when they employed the Raji cell radioimmune assay. Thus in each of these studies a method different from the one used here, was utilised.

At present all tests for immune complexes in myasthenia gravis are "antigen-nonspecific". Results depend on differing size, concentrations, and biological properties of the complexes. The Clqbinding assay is highly sensitive and similar to the anticomplementary assay in that it depends on the complex interacting with complement by reacting with a receptor on the free molecule. Thus, our results and those of Casali et al. (1976) are comparable.

The Raji cell radioimmune assay, however, depends on interaction of the complex with complement receptors on the Raji cells, and detects IgG complexes only. IgM antigen-antibody complexes (which certainly may be present in these patients) will not be identified. It is likely that complexes of more than one type are present in patients with myasthenia gravis, as has been shown in, for instance, patients with dermatitis herpetiformis and coeliac disease (Mohammed et al.,
1976). Therefore, in future it would be wise to employ several different assays for their detection.

The identity of the antigen in the immune complexes demonstrated in myasthenia gravis is unknown but in view of the fact that AChR is lost from the postsynaptic membrane, and that antibody-coated segments of receptor are shed into the postsynaptic space in both myasthenia gravis and EAMG, these complexes may represent antibody-bound receptor. Their nature awaits elucidation.

We are grateful to Professor J. A. Simpson for encouragement and for permission to study patients under his care. This work was supported by the Muscular Dystrophy Group of Great Britain.

\section{References}

Abramsky, O., Aharanov, A., Webb, C., and Fuchs, S. (1975). Cellular immune response to acetylcholine receptor-rich fraction, in patients with myasthenia gravis. Clinical and Experimental Immunology, 19, 11-16.

Aharanov, A., Abramsky, A., Tarrab-Hazdai, R., and Fuchs, S. (1975). Humoral antibodies to acetyl-O choline receptor in patients with myasthenia gravis. Lancet, 2, 340-342.

Almon, R. R., Andrew, D. G., and Appel, S. H. (1974). Serum globulin in myasthenia gravis: inhibition of $\alpha$-bungarotoxin binding to acetylcholine? receptors. Science, 186, 55-57.

Barkas, T., Harrison, R., Lunt, G. C., Stephenson, F. A., Behan, P. O., and Simpson, J. A. (1979). Acetylcholine receptor antibody titres in myasthenia gravis. In Progress in Neurological Resarch. Edited by P. O. Behan and F. Clifford Rose. Pitman Press: London. In press.

Bender, A. N., Ringel, S. P., Engel, W. K., Daniels, M. P., and Vogel, Z. (1975). Myasthenia gravis: a serum factor blocking acetylcholine receptors of the human neuromuscular junction. Lancet, 1, 607-609.

Casali, P., Borzini, P., and Zanussi, C. (1976). Immune complexes in myasthenia gravis. Lancet, $2,378$.

Castleman, B. (1966). The pathology of the thymus gland in myasthenia gravis. Annals of the New York Academy of Sciences, 135, 496-505.

Engel, A. G., Lambert, E. H., and Howard, F. M. (1977). Immune complexes (IgG and C3) at the motor end plate in myasthenia gravis: ultrastructural and light microscopic localization and electrophysical correlations. Mayo Clinic Proceedings, 52, 267-280.

Heinemann, S., Merlie, J., and Lindstrom, J. (1978). Modulation of acetylcholine receptor in rat diaphragm by anti-receptor sera. Nature, 274, 65-68.

Kent, J. F., and Fife, E. H. (1963). Precise standardization of reagents for complement fixation. Ameri- 
can Journal of Tropical Medicine and Hygiene, 12, 103-116.

Laurell, C-B. (1965). Antigen-antibody crossed electrophoresis. Analytical Biochemistry, 10, 358-361.

Lefvert, A. K., Bergstrom, K., Matell, G., Osterman, P. O., and Pirskanen, R. (1978). Determination of acetylcholine receptor antibody in myasthenia gravis: clinical usefulness and pathogenetic implications. Journal of Neurology, Neurosurgery, and Psychiatry, 41, 394-403.

Lennon, V. A., Seybold, M. E., Lindstrom, J. M., Cochrane, C., and Mevitch, R. (1978). Role of complement in the pathogenesis of experimental autoimmune myasthenia gravis. Journal of Experimental Medicine, 147, 973-983.

Lindstrom, J. M., Seybold, M. E., Lennon, V. A., Whittingham, S., and Duane, O. D. (1976). Antibody to acetylcholine receptor in myasthenia gravis. Neurology (Minneapolis), 26, 1054-1059.

Mayer, M. M. (1961). Complement and complement fixation. In Experimental Immunochemistry. Edited by E. A. Kabat and M. M. Mayer. Charles C. Thomas: Springfield, Illinois.

Mohammed, I., Holborrow, E. J., Fry, L., Thompson, B. R., Hoffbrand, A. V., and Stewart, J. S. (1976). Multiple immune complexes and hypocomplementaemia in dermatitis herpetiformis and coeliac disease. Lancet, 2, 487-490.

Nastuk, W. L., Osserman, K. E., and Plescia, O. J. (1956). Reduction in serum complement concentration in myasthenia gravis. Federation Proceedings, 15, 135-136.

Nastuk, W. L., Plescia, O. J., and Osserman, K. E. (1960). Changes in serum complement activity in patients with myasthenia gravis. Proceedings of the Society for Experimental Biology and Medicine, 105, 177-184.

Nastuk, W. L., Strauss, A. J. L., and Osserman, K. E. (1959). Search for a neuromuscular blocking agent in the blood of patients with myasthenia gravis. American Journal of Medicine, 26, 394-409.

Patrick, J., and Lindstrom, J. (1973). Autoimmune response to acetylcholine receptor. Science, 180, 871-872.

Reiness, C. G., Weinberg, C. B., and Hall, Z. W.
(1978). Antibody to acetylcholine receptor increases degradation of functional and extrajunctional receptors in adult muscle. Nature, 274, 68-70.

Richman, O. P., Patrick, J., and Arnason, B. G. W. (1976). Cellular immunity in myasthenia gravis: receptor and autologous thymocytes. New England Journal of Medicine, 294, 694-698.

Sahashi, K., Engel, A. G., Lindstrom, J. M., Lambert, E. H., and Lennon, V. A. (1978). Ultrastructural localization of immune complexes (IgG and C3) at the endplate of experimental autoimmune myasthenia gravis. Journal of Neuropathology and Experimental Neurology, 37, 212-223.

Simpson, J. A. (1960). Myasthenia gravis. A new hypothesis. Scottish Medical Journal, 5, 419-436.

Simpson, J. A., Behan, P. O., and Dick, H. A. (1976). Studies on the nature of autoimmunity in myasthenia gravis. Evidence for immunodeficiency type. Annals of the New York Academy of Sciences, 274, 382-389.

Strauss, A. J. L., Segal, B. C., Hsu, K. C., Burkholder, P. M., Nastuk, W. L., and Osserman, K. E. (1960). Immunofluorescence demonstration of a muscle binding, complement-fixing serum globulin fraction in myasthenia gravis. Proceedings of the Society for Experimental Biology and Medicine, 105, 184-191.

Tachovsky, T. G., Koprowski, H., Lisak, R. P., Theofilopoulos, A. N., and Dixon, F. J. (1976). Circulating immune complexes in multiple sclerosis and other neurological diseases. Lancet, 2, 997-999.

Thompson, R. A., and Lochmann, P. J. (1970). Reactive lysis-the complement mediated lysis of unsensitized cells. I. The characterization of indicator factor and its identification as C7. Journal of Experimental Medicine, 131, 629-641.

Toyka, K. V., Drachman, D. B., Griffin, D. E., Pestronk, A., Winkelstein, J. A., Fishback, K. H., and Kao, I. (1977). Myasthenia gravis, a study of humoral immune mechanisms by passive transfer to mice. New England Journal of Medicine, 296, 125-131.

Toyka, K. V., Drachman, D. B., Pestronk, A., and Kao, I. (1975). Myasthenia gravis: passive transfer from man to mouse. Science, 190, 397-399. 